\title{
A TELEMÁTICA COMO INSTRUMENTO DE LABOR: TELETRABALHO E HIPERCONEXÃO
}

\section{TELEMATIC AS A LABOUR INSTRUMENT: TELEWORKING AND HYPERCONNECTION}

\author{
Denise Pires Fincato \\ Pontifícia Universidade Católica do Rio Grande do Sul - PUCRS - (Porto Alegre, Rio Grande do Sul, Brasil) \\ Julise Carolina Lemonje \\ Pontifícia Universidade Católica do Rio Grande do Sul - PUCRS - (Porto Alegre, Rio Grande do Sul, Brasil) \\ Recebimento: 2 dez. 2018 \\ Aceitação: 10 abr. 2019
}

\begin{abstract}
Como citar este artigo / How to cite this article (informe a data atual de acesso / inform the current date of access):
FINCATO, Denise Pires; LEMONJE, Julise Carolina. A telemática como instrumento de labor: teletrabalho e hiperconexão. Revista da Faculdade de Direito UFPR, Curitiba, PR, Brasil, v. 64, n. 1, p. 119-136, jan./abr. 2019. ISSN 2236-7284. Disponível em: <https://revistas.ufpr.br/direito/article/view/63698>. Acesso em: 30 abr. 2019. DOI: http://dx.doi.org/10.5380/rfdufpr.v64i1.63698.
\end{abstract}

\section{RESUMO}

Este artigo tem como objetivo analisar a vulnerabilidade de teletrabalhadores à hiperconexão, tendo em vista a expansão do regime de teletrabalho e a sua recente regulação, no território nacional, pela Lei n. 13.467/2017 (Reforma Trabalhista). Por meio de abordagem dialética, e recorrendo-se a contribuições da doutrina, de artigos científicos e articulações com dispositivos legais, busca-se esclarecer aspectos referentes ao direito à desconexão do trabalho como tutela que emerge da reiterada e exagerada utilização de dispositivos telemáticos pelos trabalhadores, possibilitando o adentramento das demandas laborais nos períodos reservados ao seu descanso. Na medida em que o regime de teletrabalho passa a estar regulamentado no ordenamento jurídico brasileiro, via alteração da Consolidação das Leis do Trabalho, e contando com características próprias, tais como a prestação de serviços exclusivamente por meio do uso de tecnologias, importa desenvolver exame detalhado quanto à tutela do direito à desconexão destes empregados, bem como ao cabimento ou não do controle de jornada dos teletrabalhadores.

PALAVRAS-CHAVE

Teletrabalho. Hiperconexão. Controle de jornada. Lei n. 13.467/2017. Direito à desconexão.

\begin{abstract}
This article aims to analyze the vulnerability of teleworkers to hyperconnection, in view of the expansion of the teleworking regime and its recent regulation in the Brazilian territory by Law $\mathrm{n}$. 13,467/2017 (Labor Reform). Through a dialectical approach, and using contributions from doctrine, scientific articles and articulations with legal devices, there is a pursue to clarify different aspects concerning the right to disconnect from work as tutelage arising from repeated and exaggerated use of telematics devices by workers, enabling working demands to trespass rest hours. To the extent that the teleworking system becomes regulated in the Brazilian legal system, through changes to the Consolidation of Labor Laws, and having its own characteristics, such as the provision of services
\end{abstract}


exclusively through the use of technologies, it is important to develop a detailed examination about the protection of these employees' right to disconnect, as well as discuss whether or not the control of teleworkers' day-to-day work is in order.

\section{KEYWORDS}

Teleworking. Hyperconnection. Control of working hours. Brazilian Law n. 13.467/2017. Right to disconnect.

\section{INTRODUÇÃO}

A expansão da modalidade de teletrabalho como alternativa a problemas de mobilidade urbana e à urgente necessidade de promover medidas visando à mitigação de impactos ambientais é viabilizada a partir do desevolvimeno das tecnologias de informação e comunicação (TICs) na era da informação. Destaca-se que a prestação de serviços mediante teletrabalho encontra estímulo em aspectos próprios dos modos de produção desenvolvidos no pós-fordismo, que buscam empregados polivalentes e flexíveis, de maneira que a possibilidade de acessar conhecimento e profissionais qualificados sem empecilhos espaciais apresenta-se como um importante benefício às organizações em busca de desenvolvimento.

Neste contexto, importa destacar a inserção de dispositivos informáticos e comunicacionais no ambiente de trabalho, o que, a partir da facilitação do contato instantâneo, prejudica a distinção entre os momentos dedicados às demandas profissionais e os reservados à vida privada e ao lazer. $\mathrm{Na}$ medida em que o exercício da atividade laboral não tem mais como limite as dependências do empregador, atenta-se à continuidade da jornada de trabalho para além dos limites previstos contratual e, sobretudo, constitucionalmente. É nesta conjuntura, em que os empregados encontram possibilidade de contínua troca de informações com o empregador, bem como fácil acesso às tarefas laborais a qualquer tempo, que o direito a desconectar-se de seu trabalho emerge.

Por conseguinte, a análise da hiperconexão de teletrabalhadores justifica-se na medida em que a prática encontra, na era da informação, espaço propício à sua consolidação enquanto modalidade de trabalho e, a partir do uso de equipamentos telemáticos como instrumentos e ambientes de trabalho, os teletrabalhadores estão expostos à conexão constante com sua dimensão existencial laboral. Tendo em vista as consequências individuais e coletivas do adentramento das tecnologias em ambiente de trabalho e do excesso de jornada, a análise da possível lesão ao direito à desconexão de empregados adeptos ao regime de teletrabalho, bem como o desenvolvimento de reflexões acerca das alterações da Lei $n^{0}$ 13.467/2017 no que se refere à modalidade, apresentam pertinência jurídicoacadêmica e social. 
A partir do método dialético, aportando contribuições reflexivas fundamentadas por pesquisa de doutrina, artigos científicos e articulações com dispositivos legais, o presente artigo pretende contribuir à pesquisa do teletrabalho e do direito à desconexão, bem como tecer conclusões referentes à possível vulnerabilidade do teletrabalhador à hiperconexão e a respectiva tutela de seu direito a desconectar-se.

\section{TELETRABALHO SUBORDINADO: CONCEITO E CARACTERÍSTICAS}

Impulsionado pelo incremento no acesso e aperfeiçoamento das tecnologias de informação e comunicação (TICs), o teletrabalho alcança cada vez mais relevância em contexto nacional - fato evidenciado pela atenção dada ao tema pela Lei $n^{0}$ 13.467/2017 (Reforma Trabalhista) - e internacional. Tendo em vista que na modalidade do teletrabalho os equipamentos telemáticos consistem em instrumentos (e, por vezes, ambientes) de trabalho, os teletrabalhadores encontram possibilidade constante de conexão com suas demandas laborais, de maneira que importa a análise da garantia ao direito à desconexão do empregado em regime de teletrabalho.

O teletrabalho, que encontra no desenvolvimento das novas tecnologias de informação meios para consolidar-se como uma modalidade em ascensão no contexto laboral, é definido por Pedreira (2000, p. 584) como a atividade do trabalhador desenvolvida total ou parcialmente em locais distantes da sede principal da empresa, por uso de meios telemáticos. Amauri Mascaro Nascimento e Sônia Mascaro Nascimento (2014, p. 1.056) entendem teletrabalho como o trabalho não executado no estabelecimento do empregador e cuja realização se dá por meio da utilização de meios de comunicação. Os autores salientam que, além do trabalhado realizado em casa, a prestação dos serviços por meio de centros localizados fora da empresa também pode caracterizar-se como teletrabalho.

Ainda no que diz respeito à conceituação do teletrabalho, enfatiza-se que a interferência tecnológica é central na caracterização desta modalidade, devendo o trabalho ser realizado mediante “ferramentas próprias, tais como computadores, telefones ou quaisquer outros aparelhos que sejam classificados como pertencentes à TIC (Tecnologia da Informação e da Comunicação)” (RESEDÁ, 2007, p. 162). Importa assinalar que os serviços podem ser realizados total ou parcialmente distantes da sede ou filial da empresa; ou, como definem Fincato e Cracco Neto (2013, p. 54), em regime puro - todo o período laborado cumpre as características do teletrabalho - ou híbrido, em que parte do trabalho é realizada no ambiente físico da empresa. 
Embora a prestação de serviço do empregado teletrabalhador ocorra fora do espaço físico do empregador, é possível identificar-se o elemento da subordinação, típico das relações de emprego. Autores como Dutra e Villatore (2014, p. 143) afirmam que a subordinação encontra-se mitigada e atenuada na relação de teletrabalho e incide não sobre a pessoa, mas sobre o serviço por ela realizado. Afonso (2017, p. 722-723), em contrapartida, afirma que o regime de teletrabalho não impede o exercício do poder diretivo e fiscalizatório do empregador em relação ao empregado, visto que há plena possibilidade de fiscalização do trabalhador por meios informáticos como webcam e softwares. Neste sentido, o autor aponta o teletrabalho como ferramenta que permite aos empregadores a contratação de mão de obra a ser prestada à distância, sem prejuízo à fiscalização do trabalho executado.

Fincato (2006, p. 55) aduz que a apresentação de alguns elementos da relação de emprego de forma mais tênue e rarefeita não exclui a sua presença e apreciação. Nesta perspectiva, as singularidades do vínculo entre empregado e empregador em contextos de teletrabalho não enseja a desconsideração da existência de subordinação, dado que o cumprimento das tarefas, bem como a qualidade das mesmas, estão sujeitos à avaliação e a novas orientações.

Em consonância com o entendimento de que há subordinação nas relações de teletrabalho, por conta da fiscalização em tempo integral permitida pelo uso da tecnologia, os teletrabalhadores podem estar ainda mais subordinados do que empregados que laboram em ambientes físicos (MELO, 2016, p. 233). Neste sentido, Estrada (2014, p. 34-35) expõe que a visão de teletrabalhadores livres está equivocada, uma vez que estes às vezes se encontram submetidos a uma dependência tão intensa quanto, ou ainda mais, que a que teriam se estivessem trabalhando nos locais da empresa, considerando a possibilidade de fiscalização constante e a proposição de metas que o empregador possui.

A partir da evidente possibilidade de exercer o poder diretivo por meio de instrumentos telemáticos, resta evidenciado que o teletrabalho preenche os requisitos necessários para sua caracterização como relação empregatícia. Assim sendo, merece respaldo da legislação protetiva em mesma medida que o trabalho realizado no ambiente físico da sede ou filial da empresa, entendimento que se encontra pacificado nos tribunais brasileiros. Além da equiparação do teletrabalhador aos demais empregados mediante a alteração do artigo $6^{\circ}$ da Consolidação das Leis do Trabalho (CLT) 
em $2011^{1}$, também enseja tal compreensão a inclusão, pela Lei no $13.467 / 2017$, do Capítulo II-A na CLT, dispondo sobre o teletrabalho.

\section{BENEFÍCIOS E IMPACTOS DA MODALIDADE AO TELETRABALHADOR}

A literatura, ao analisar a prestação de serviços mediante teletrabalho, aponta diversas vantagens, dentre as quais destaca-se a maior flexibilidade de horários para a conciliação da vida profissional com demandas pessoais (ALMEIDA; SEVERO, 2016, p. 47), bem como benefícios relacionados à redução de deslocamentos e de gastos com vestimentas e outras variáveis inerentes ao trabalho tradicional. Em análise da aplicação da modalidade em empresas no Brasil, Ribeiro (2016) aponta que os empregados que praticam teletrabalho encontram satisfação profissional decorrente do ganho de autonomia e do empreendedorismo de si próprio, verificando que, embora os empregados pontuem também aspectos negativos, os benefícios superam os custos para os teletrabalhadores da empresa objeto do estudo, sendo a principal vantagem indicada a flexibilidade de horários.

O empregador, por sua vez, encontra vantagens financeiras na adoção da modalidade de teletrabalho em sua empresa, ao evitar despesas com a locação de imóveis e demais investimentos relacionados à infraestrutura necessária para acomodação dos trabalhadores (MELO, 2016), além da possibilidade de acessar talentos e profissionais qualificados ao cargo em outras regiões e países. Constata-se, também, a redução do absenteísmo e da rotatividade, uma vez que parte das licenças são utilizadas para resolução de problemas pessoais, bem como a diluição do risco de paralisação de atividades da empresa em situações de força maior (LUCENA, 2015, p. 53-55).

As vantagens de dispensar o deslocamento até a sede da empresa vão além do âmbito individual, sendo possível identificar sua relação com importantes questões sociais. Ao reduzir significativamente a quantidade de deslocamentos de empregados que diariamente dirigem-se ao estabelecimento do empregador, diminui-se o uso de combustíveis fósseis e a emissão de gases poluentes. Ademais, a sociedade se vê beneficiada em aspectos referentes à inclusão social, conforme afirmam Bald e Tessmann (2016, p. 163-164), que indicam o teletrabalho como potencialmente redutor de desigualdades sociais na medida em que pode oferecer a integração de pessoas que vivem em regiões desfavorecidas e com dificuldade de acesso ao transporte público, bem como de pessoas com mobilidade reduzida.

\footnotetext{
${ }^{1}$ A alteração decorrente da Lei 12.551 de 2011, além de modificar o texto do artigo $6^{\circ}$ da Consolidação das Leis do Trabalho (CLT), acrescentou o parágrafo único do referido dispositivo pacificando o entendimento no sentido de que a subordinação se caracteriza mesmo quando o poder de mando se dá por meios telemáticos e informatizados.
} 
Todavia, ao revisar literatura sobre o tema, observaram-se também ameaças à saúde dos empregados em regime de teletrabalho; dentre estes riscos, enfatizam-se, por aderência temática, os relacionados à hiperconexão de teletrabalhadores. Para Barros (2013, p. 260), o sucesso do empregado na diferenciação de “tempo de trabalho" e "tempo livre” é um importante meio para que os teletrabalhadores desfrutem efetivamente das vantagens do trabalho à distância. No mesmo sentido, Resedá (2007, p. 164) salienta o risco de prolongamento da jornada de trabalho em decorrência da flexibilização de horários, considerando a mitigação da barreira entre os momentos dedicados ao trabalho e os voltados ao lazer.

Sendo assim, a autodisciplina para delimitar e gerir o próprio tempo e diferenciar ambientes é de extrema importância para que o empregado possa ser favorecido pelas comodidades do teletrabalho. Nesse sentido, Melo (2016, p. 238) refere a importância de capacidade autorregulatória por parte dos empregados em regime de teletrabalho, enquanto Santos e Miranda (2017) tratam a proteção do limite de jornada do teletrabalhador em uma perspectiva de corresponsabilidade entre empregado e empregador, afirmando que além de o empregador abster-se de demandar o empregado fora do período de trabalho, deve haver uma disciplina do próprio empregado para que não consulte material relativo ao trabalho quando encerrada a jornada.

\section{A DILUIÇÃO DE BARREIRAS E A CONEXÃO NO TELETRABALHO}

Tendo em vista que o uso das tecnologias de informação e comunicação é elemento necessário para a caracterização da prestação de serviços na modalidade de teletrabalho (RESEDÁ, 2007, p. 162), a atividade laboral é exercida por meio de equipamentos tecnológicos, e as barreiras que antes limitavam o trabalho ao espaço físico do empregador - que restam diminuídas em grande parte das relações laborais - são completamente derrubadas em contextos de teletrabalho. A mistura de ambientes pode tornar-se tão intensa a ponto de provocar a subtração do ambiente privado por conta da ausência de desconexão (BRAGA, 2015, p. 140); nesses casos, a dimensão pessoal e familiar do empregado resta capturada e cronicamente enfraquecida pela atividade profissional do teletrabalhador.

As consequências de deslocar o trabalho para dentro do lar impactam também o relacionamento familiar, na medida em que o teletrabalho exercido em casa demanda da família e dos demais que compartilham o ambiente doméstico a necessidade de reorganizar-se no que diz respeito a papéis exercidos por cada membro, horários de silêncio e respeito ao material profissional do teletrabalhador. A carência de uma reeducação de filhos e companheiros a esta nova estrutura pode 
implicar dificuldades de concentração e perda de produtividade do teletrabalhador, fazendo com que este se veja obrigado a trabalhar continuamente, jamais se desconectando, a fim de alcançar, em meio às distrações familiares, as metas propostas (TARGINO, 1995, p. 199).

Nesta conjuntura, tanto a portabilidade dos instrumentos de trabalho (MARQUES, 2017, p. 84) - uma vez que equipamentos telemáticos estão disponíveis ao empregado constantemente -, como a recorrente transformação do lar em ambiente laboral, tornam o trabalhador vulnerável à hiperconexão, haja vista que a inserção da empresa na intimidade do empregado gera a possibilidade de se trabalhar a todo o tempo (RESEDÁ, 2007, p. 164). Nunes (2016, p. 204-205) argumenta que o excesso de jornada consiste em uma das principais ameaças ao êxito na adoção do regime de teletrabalho, tendo em vista as consequências prejudiciais à saúde do empregado decorrentes da exaustão - para a autora, as vantagens da modalidade restam ameaçadas pela carência de controle de horários e pelo excesso de cobranças por produtividade.

Desta forma, a falta de desenvolvimento de estratégias de diferenciação entre ambientes e o uso inadequado das tecnologias de informação, somados à grande demanda mediante estabelecimento de metas presente em contextos de trabalho à distância, torna o teletrabalhador vulnerável à hiperconexão por não conseguir liberar-se da atmosfera profissional, impedindo-o de se afastar das questões pertinentes ao seu emprego e não sanadas ao longo da jornada.

O direito a desconectar-se do trabalho apresenta fundamental importância ao se investigar a saúde e demais condições laborais do teletrabalhador. Considerando que o exercício de suas funções se dá inevitavelmente por meio das tecnologias de informação e comunicação, tem-se um aumento na complexidade da análise e da tutela da desconexão deste empregado. O fato de as condições laborais do teletrabalhador orbitarem no "estar-conectado" torna o seu ambiente laboral propenso a uma sobreposição do lazer, das responsabilidades pessoais e do trabalho, especialmente pela conexão ininterrupta.

\section{IMPACTOS DA HIPERCONEXÃO DO TRABALHADOR}

Souto Maior (2003) utilizou o termo “direito à desconexão” para fazer referência ao direito ao não trabalho, acrescentando que, ao falar em direito à desconexão, faz referência a um direito na perspectiva técnico-jurídica, tratando o não trabalho como um bem da vida e havendo perspectiva de deduzir a pretensão de protegê-lo em juízo. Assim, entende-se o direito à desconexão como a liberdade do individuo de usar o seu tempo de vida livremente e como lhe parecer conveniente - sem 
estar vinculado às suas demandas laborais (HARFF, 2017, p. 57) -, além de não sofrer interrupções em seus períodos de intervalos e férias.

Em atenção às repercussões das novas tecnologias nas relações de trabalho, o direito à desconexão nasce da moderna relação entre tecnologia e trabalho, tendo em vista que a dificuldade de desconectar-se torna cada vez mais frágil a linha entre o trabalho e os momentos de vida privada e descanso - como férias, finais de semana e intervalos entre jornadas (MELO, 2016, p. 241). Almeida e Severo (2016, p. 26), ao analisar a tutela dos referidos períodos de descanso dos trabalhadores, aludem à necessidade de tratar o assunto a partir da concepção do direito constitucional a "estar fora do trabalho, física e mentalmente, durante e após a jornada”, considerando que limites de jornada estão expressamente estabelecidos nos incisos do artigo $7^{\circ}$ da Carta Magna.

Ao identificar a intrínseca relação do tema com demais garantias constitucionais, Oliveira (2010) indica que o direito à desconexão não consiste em um direito “novo”, mas caracteriza-se pelo reconhecimento de elementos derivados de outros direitos por meio de processos de transmutação hermenêutica e de criação jurisprudenciais. Sendo assim, o direito à desconexão visa a proteção de bens tutelados por direitos já consolidados em nosso ordenamento jurídico - lazer, descanso, privacidade, saúde -, com especial atenção a um contexto em que a comunicação e o recebimento de informações tornaram-se ininterruptos e a saída da empresa ao fim da jornada não garante o afastamento das responsabilidades laborativas do empregado.

O sofrimento de ingerências em períodos de descanso constitucionalmente garantidos - que normalmente se destinam a ocupações desvinculadas do contexto laboral - gera prejuízos tanto ao trabalhador que tem seu repouso lesado quanto à sociedade, haja vista que o excesso de trabalho prejudica dimensões distintas da esfera social do empregado, como o exercício da cidadania. Um trabalhador que jamais se desconecta de seu trabalho se vê indisposto para atuar politicamente na sociedade e, até mesmo, para auxiliar na promoção de um ambiente familiar saudável (SOUTO MAIOR, 2003, p. 21-22).

Fincato e Marques (2016, p. 40), ainda, contribuem demonstrando a relevância da tutela do direito à desconexão também aos empregadores, afirmando que é de interesse destes a manutenção da higidez do empregado e do coletivo de trabalhadores, defendendo a inerência do direito à desconexão a todo trabalhador, ebque os benefícios do gozo desta garantia proporcionam vantagens não só para empregado e seus familiares, mas também para o empregador e o sistema econômico em si.

Ainda, o potencial cognitivo - e criativo - do trabalhador é diretamente afetado por suas condições físicas e psicológicas, de maneira que trabalhadores exaustos têm seu desempenho 
prejudicado e se desperdiçam possibilidades de maior qualificação profissional (ALMEIDA; COLNAGO, 2016, p. 119).

A hiperconexão de trabalhadores também gera importantes impactos à sociedade no que diz respeito à transmissão de cultura. O patrimônio cultural se vê afetado pela hiperconexão do empregado na medida em que guarda nas relações intersubjetivas a possibilidade de desenvolver-se e conservar-se (LUNARDI, 2008, p. 104), e estas relações restam prejudicadas com a exaustão do trabalhador decorrente do excesso de jornarda. Neste sentido, Souto Maior (2003, p. 8) afirma que o titular do direito à desconexão não é apenas o empregado, mas a própria sociedade. Além de condenações determinando o pagamento de adicional de hora extra quando se leva ao Poder Judiciário a lesão ao direito a desconectar-se, os excessos de jornada mediante hiperconexão ao trabalho têm sido entendidos, também, como geradores de outros danos extrapatrimoniais, se demonstrado que a prática afrontou direito social (AFONSO, 2017, p. 726), podendo ser caracterizado, por exemplo, o dano existencial, entendindo este como uma espécie de dano à pessoa, que compreende todos os prejuízos que seguem o ilícito e que envolvem uma modificação pejorativa da esfera pessoal do sujeito lesado, concretizando-se, mais especificamente, no comprometimento das várias atividades não lucrativas do indivíduo e que objetivam a plena realização da própria personalidade².

Atenta às complexas consequências da inserção de tecnologias nas relações de trabalho e ao direito a desconectar-se, a reforma trabalhista francesa ocorrida no ano de 2016, conhecida como “Loi Travail” ou “Loi El Khomri”, contemplou dispositivos refentes ao direito à desconexão. Marcada por flexibilizações e pela outorga de poder às negociações coletivas visando incrementar a competitividade das empresas francesas, a reforma ocorrida na França determinou a inclusão do direito à desconexão entre as matérias tratadas em negociação coletiva anual obrigatória. Nesta oportunidade, deverão ser estabelecidos dispositivos que regulem o uso de ferramentas digitais, objetivando o efetivo cumprimento dos períodos de intervalos e férias, além de tutelar o respeito à vida pessoal e familiar do empregado (HARFF, 2017, p. 69).

O encargo de tratar do direito à desconexão, seguindo o discurso da reforma francesa, foi delegado aos acordos coletivos visando que cada categoria estabeleça aparatos de controle adequados à realidade da atividade desempenhada (HARFF, 2017). Desta forma, a regulamentação do direito à desconexão tende a ser uma necessidade, considerando a inserção das tecnologias de informação e

\footnotetext{
2 "Il danno esistenziale, quale species del danno alla persona, ricomprende tutti i pregiudizi che conseguono all'intelecito e che comportano una modificazione peggiorativa della sfera personale del soggeto leso, concretizzandosi, più specificamente, nella compromissione dele varie attività non reddituali che il singolo svolge in ordine ala piena realizzazione della propria personalità.” CHRISTANDL, Gregor. La risarcibilità del danno esistenziale. Milão: Giuffrè, 2007, p. 244-245.
} 
comunicação no ambiente laboral e os riscos individuais e sociais decorrentes do seu uso inadequado. Ainda, importa salientar que a existência de disposição legal sobre o tema também promove maior segurança ao empregador, tendo em vista que atualmente não há clareza quanto aos mecanismos de modulação do uso de equipamentos tecnológicos dentro e fora das empresas.

\section{DIREITO À DESCONEXÃO DO TELETRABALHADOR: CONTROLE DE JORNADA E APLICAÇÃO DO ARTIGO 62, III, DA CLT}

No Brasil, a propensão à ausência de limitação do tempo dedicado ao trabalho - e, consequentemente, a lesão ao direito à desconexão do teletrabalhador - intensifica-se com a desobrigação de controle de jornada deste empregado, estabelecida com o acréscimo do inciso III ao artigo 62 da CLT pela Lei n ${ }^{\circ}$ 13.467/2017 (Reforma Trabalhista), cujo texto determina a não aplicação do capítulo celetista referente à duração da jornada aos trabalhadores em regime de teletrabalho ${ }^{3}$. Na medida em que os teletrabalhadores não têm o seu período dedicado às demandas laborais controlado, estes se encontram em situação similar à dos trabalhadores franceses que ocupam altos cargos, principais destinatários da norma francesa que trata do direito a desconectar-se do trabalho. Sendo assim, importa a análise da vulnerabilidade do teletrabalhador à hiperconexão, bem como da possibilidade de controle de jornada.

Ao analisar a conjuntura do ambiente laboral no teletrabalho e o possível controle de jornada do teletrabalhador, autores veem os meios telemáticos como artifícios não somente para direcionar a prestação de serviços, mas também para realizar o controle do volume de horas trabalhadas, ainda que o empregado esteja fora das dependências do empregador (ALMEIDA; COLNAGO, 2016, p. 118-119). Desta forma, o controle de horário nos casos em que o trabalho não é realizado nas dependências da empresa pode ser substituído por indícios existentes em outros instrumentos que estão presentes na atividade do teletrabalhador, como o correio eletrônico e programas de comunicação instantânea (MEDEIROS, 2015, p. 507).

Haja vista que o labor é exercido por meio de conexão com o empregador - e desta atividade se têm registros referentes ao encaminhamento de e-mails, quantidade de tempo em que o empregado permaneceu utilizando o sistema da empresa, bem como dados relacionados ao uso de smartphones para fins profissionais -, a tecnologia se apresenta, muitas vezes ${ }^{4}$, como viabilizadora ao controle das

\footnotetext{
${ }^{3}$ Art. 62. Não são abrangidos pelo regime previsto neste capítulo: [... ] III - os empregados em regime de teletrabalho. In: BRASIL. Lei n. 13.467, de 13 de julho de 2017. Disponível em: http://bit.ly/2V9bvtz. Acesso em: 11 out. 2017.

${ }^{4}$ Ponderando-se as atividades que, por carecerem de conexão com a empresa, têm seu tempo laborado efetivamente fora da gestão do empregador.
} 
horas trabalhadas e, também, como o próprio recurso para conter a atividade laboral do empregado às horas contratadas ou, se não contratadas, em consonância com a carga máxima estipulada na legislação vigente.

Quanto ao uso da telemática para proteção dos teletrabalhadores, a multinacional Unilever - em que 73\% dos funcionários elegíveis para o teletrabalho desempenham suas atividades à distância uma ou duas vezes por semana - oportunizou treinamento aos funcionários escolhidos para que aprendessem a respeito do novo sistema e desenvolvessem habilidades para o trabalho longe do escritório. A fim de evitar exposição a ações judiciais, a empresa implantou um modelo em que os teletrabalhadores possuem hora certa para começar e terminar a jornada ${ }^{5}$ e no qual o sistema de acesso aos arquivos da empresa cai quando o expediente termina (STEFANO; ROSSI, 2015).

A possibilidade de alinhamento entre a flexibilidade e a delimitação do controle de jornada também é apontada por Betiatto (2017) que, ao analisar a recente normativa italiana - Legge 22 maggio 2017, n. 81 -, destaca a determinação em seu texto para que o trabalho seja realizado de acordo com a jornada estabelecida em lei ou acordo, sem necessariamente vínculo de horário e local de trabalho ${ }^{6}$. Ainda, o autor entende que para a proteção do teletrabalhor deve-se articular um paralelo ao ato de anotar a saída no cartão de ponto, evitando o excesso de jornada do empregado adepto ao regime.

Em contrapartida, Ravagnani e Rodrigues (2018) sublinham que a mensuração da jornada de trabalho enfrenta obstáculos em decorrência de elementos intrínsecos à essência do teletrabalho, quais sejam: a autonomia e a flexibilidade de horário para execução das atividades. Sendo assim, ainda que reconhecida a subordinação do teletrabalhador, tal elemento não atrairia absolutamente todos os aspectos de uma relação de emprego tradicional, haja vista as peculiaridades inerentes à forma como o serviço é prestado. Atentos à divergência doutrinária no que diz respeito ao direito do teletrabalhador a perceber o pagamento de horas extras quando sujeito à sobrejornada, os autores reconhecem que a limitação constitucional de horas a serem trabalhadas não pode ser olvidada.

Quanto à constitucionalidade do inciso III do art. 62, Bezerra Leite (2017, p. 502) afirma que, em que pese existam movimentos doutrinários apontanto a violação à Constituição Federal pelo dispositivo, o entendimento majoritário é no sentido de sua constitucionalidade. Destaca, todavia, que a vigência do dispositivo não afasta o princípio da primazia da realidade, de maneira que, se possível

\footnotetext{
${ }^{5}$ Neste caso, diante da nova lei, a empresa estaria criando condição contratual peculiar, que deve ser observada, abrindo mão da presunção contida no art. 62, III, da CLT.

6 “senza precisi vincoli di orario o di luogo di lavoro". ITÁLIA. Legge 22 maggio 2017, n. 81. Disponível em: http://bit.ly/2v6fLvo. Acesso em: 28 jun. 2018.
} 
o controle de jornada, o teletrabalhador fará jus às horas extraordinárias trabalhadas além do limite legal.

Neste sentido, doutrinadores (DELGADO; DELGADO, 2017, p. 133) indicam que a regra instituída a partir do artigo 62, III, trata-se de presunção relativa - isto é, que o empregado, na medida em que presta serviços na modalidade de teletrabalho, está exercendo atividade incompatível com o controle de jornada e, consequentemente, o empregador se vê isento da realização do referido controle. Conforme Delgado e Delgado (2017), tal presunção pode ser desconstituída com prova em contrário ${ }^{7}$. Em consonância com este entendimento, a interpretação do artigo 62, III, deve ser feita tão somente nos casos em que não há fiscalização do teletrabalhador (MAGALHÃES, 2017, p. 294).

Por conseguinte, a aplicação do dispositivo é devida, uma vez que positivado em nosso ordenamento; porém, da mesma maneira como se aplica o texto nos demais incisos do artigo referentes a gerentes e trabalhadores externos -, o telempregador apenas estará desincumbido de arcar com direitos relativos à jornada de trabalho, como o pagamento de horas extraordinárias, quando o empregado adepto ao teletrabalho efetivamente não tenha sua jornada controlada, isto é, quando desempenhar suas tarefas de tal modo que seu serviço seja incompatível com o controle. Desta forma, a exclusão de teletrabalhadores da aplicação do capítulo relativo à jornada de trabalho não poderia ser descolada de um critério prático, analisado a partir da natureza e método de desempenho das atribuições do empregado (LIMA FILHO; BRASIL, 2018).

Importa destacar, todavia, que se constata uma inclinação à fiscalização do teletrabalhador mediante o controle de seu desempenho. Considerando que o teletrabalho consiste em uma modalidade de trabalho - abrangendo diferentes profissões e funções -, reconhece-se que atividades diversas podem aderir ao regime e que, consequentemente, apresentarão diferentes cenários. Mross (2016, p. 30) indica como atividades passíveis de serem teletrabalhadas aquelas que possibilitam mensuração objetiva em termos de prazos e qualidade, enquanto Nilles (1997, p. 35), conhecido como “pai do teletrabalho", afirma que a verificação da adequação de uma atividade ao teletrabalho se dá a partir da análise de suas exigências, avaliando as tarefas desempenhadas pelo cargo.

A partir do reconhecimento de que diferentes funções são desempenhadas por teletrabalhadores, faz-se necessário diferenciá-las quanto à possibilidade e modo de fiscalização -

\footnotetext{
${ }^{7}$ Souto Maior entende que da alegação de impossibilidade de controle de jornada deriva ao empregador o ônus da prova - compreensão contrária à de doutrinadores como Mauricio Godinho Delgado e Carlos Henrique Bezerra Leite, que afirmam que para a não aplicação do artigo 62 da CLT deve-se demonstrar a possibilidade de controle, sendo esta demonstração encargo do empregado.

${ }^{8}$ Na década de 70, Nilles reconheceu no trabalho à distância - especialmente no trabalho em domicílio - oportunidade para reduzir os custos provenientes do alto preço do petróleo. A proposta foi denominada pelo idealizador de "telecommuting" e se utilizava de meios como correio, telegramas e telefonemas.
} 
uma vez que apresentam diferentes níveis de conexão ao empregador. Há atividades em que ocorre o constante contato com o empregador ou em que o empregado encontra-se conectado ao sistema da empresa, pelo menos por um período mínimo diário para o desempenho de suas atividades - nestes casos, é possível identificar a fiscalização do teletrabalhador e, portanto, a possibilidade de aplicação dos dispositivos celetistas referentes à duração do trabalho.

Todavia, também se admite que algumas atividades, ainda que realizadas por meio de tecnologias de informação e comunicação, não pressupõem a conexão com o empregador - e este tem pouco conhecimento sobre o tempo dedicado pelo teletrabalhador ao desenvolvimento das atividades laborais. Sendo assim, nos casos em que efetivamente o controle do trabalho prestado se dá apenas por meio da entrega de tarefas - a título de exemplo, pode-se apontar as atividades criativas, como a criação de websites -, não estando presente a conexão do trabalhador à empresa durante o desenvolvimento do serviço, a aplicação do artigo 62 mostra-se cabível, a fim de evitar punições ao empregador em decorrência de fatos que escapam de seu domínio, bem como prevenir a resistência à adoção do regime de teletrabalho por parte de empresas, visto que poderão identificar na modalidade risco de futuras demandas judiciais.

Cumpre destacar, ainda, que o teletrabalho requer profissionais dotados de capacidade autorregulatória, tendo em vista a necessidade de disciplinar o tempo despendido com as tarefas profissionais a fim de preservar seus períodos de descanso (MELO, 2016, p. 246). No sentido de analisar a dupla responsabilidade pela desconexão do trabalho, Harff (2017, p. 64) traz à discussão a corresponsabilidade do empregado, atentando que a capacidade de se desconectar também depende das relações de cada indivíduo com o próprio tempo e, acrescenta-se, com a tecnologia.

Verifica-se, portanto, a necessidade de proteção ao direito à desconexão dos teletrabalhadores em decorrência da possibilidade de constante utilização dos meios telemáticos, instrumento de trabalho do empregado adepto à modalidade. Desta forma, deve-se buscar a promoção de uma relação equilibrada entre as demandas laborais e as atividades pessoais do indivíduo. Ainda, importa salientar a relevância de regulamentação clara quanto ao teletrabalho e os mecanismos de controle de jornada, estipulando responsabilidades não apenas ao empregador, mas também promovendo mecanismos de autodisciplina por parte do empregado.

Ademais, o estudo das possibilidades de efetivo controle de jornada mediante o uso das tecnologias de informação e comunicação mostra-se de fundamental importância para a análise da adequação da aplicação do artigo 62 da CLT aos teletrabalhadores. Na medida em que o texto do dispositivo é presunção relativa reveladora da opção política do legislador no momento da elaboração do texto legal e que o controle de jornada evidencia-se como importante meio de proteção ao direito 
à desconexão, é válida a discussão a respeito da real dificuldade e impraticabilidade da realização deste controle em contextos de teletrabalho, assim como o acerto ou não desta opção políticolegislativa.

\section{CONCLUSÃO}

A partir da análise das particularidades do exercício laboral mediante teletrabalho, que tem no uso de tecnologias de informação e comunicação seu instrumento e ambiente, evidenciou-se a relevância e pertinência do presente estudo. Apesar de o regime de teletrabalho apresentar inúmeras vantagens - abrangendo não apenas benefícios ao empregado e ao empregador, mas também à sociedade -, observam-se, também, riscos à saúde de empregados adeptos ao regime de teletrabalho.

O esmaecimento das barreiras entre o ambiente laboral e o pessoal, agravado pela prestação de serviços em local diverso do estabelecimento do empregador, promove a facilitação e o estímulo à constante conexão ao trabalho. Ademais, as alterações provenientes da Lei nº 13.467/2017 (Reforma Trabalhista), especialmente o acréscimo do inciso III ao artigo 62 da CLT, merecem destaque ao se falar de direito à desconexão de teletrabalhadores, uma vez que exime os teleempregadores de realizar o controle de jornadas de seus empregados - e, consequentemente, coloca-os em uma situação distinta no ordenamento jurídico, no que diz respeito ao controle do tempo laborado.

Não obstante a desobrigação do controle de jornada prevista no artigo 62, III, a partir do estudo realizado identifica-se a factibilidade do controle de jornada por meio de equipamentos telemáticos que, além de possibilitarem a realização do trabalho à distância - concretizando-se como instrumentos de labor -, permitem a fiscalização do teletrabalhador. Na medida em que o empregado se encontra em constante conexão com supervisores ou com o sistema da empresa, torna-se viável a tutela de seu direito à desconexão, mediante o controle dos períodos trabalhados, o que, se em discordância com os limites constitucionais, sujeita o empregador às respectivas sanções.

Ainda que evidenciada a frequente conexão de teletrabalhadores ao seu empregador, admitese que algumas atividades teletrabalhadas não pressupõem a conexão com o empregador - e que este tem pouco conhecimento sobre o tempo dedicado pelo teletrabalhador ao desenvolvimento das atividades contratadas. Nestes casos, entende-se pela coerência da aplicação do artigo 62, III, da CLT, evitando que o empregador reste prejudicado pela alegação de fatos que não estão sob seu império ou, até mesmo, que se crie resistência imerecida ao regime de teletrabalho, especialmente nos casos em que o empregador controla e retribui o trabalho exclusivamente com base no desempenho. 
Ainda, em consideração às variáveis pessoais que perpassam a hiperconexão ao trabalho, importa observar o contexto em que este fenômeno ocorre; isto é, uma conjuntura em que a permanente conexão a dispositivos telemáticos também está presente na esfera pessoal, permitindo falar, inclusive, em uma nova existência humana. Sendo assim, atenta-se aos casos em que o teletrabalhador se mantém conectado às suas atividades profissionais não por conta de ingerências de seus supervisores ou demandas excessivas, mas por optar pela continuidade da conexão ao trabalho, tendo em vista o atrofiamento de barreiras, próprio da era informatizada. Nestes casos, por vezes, escapa do controle do empregador a continuidade da jornada do empregado para além dos limites constitucionais, sendo indicado ao empregador o treinamento e acompanhamento do teletrabalhador.

Em atenção à vulnerabilidade do teletrabalhador e à tendência a manter-se hiperconectado, enfatiza-se a importância de regulamentação clara quanto à modalidade de teletrabalho e em relação aos mecanismos - e hipóteses - de contole de jornada, contemplando tanto as responsabilidades do empregador quanto o estabelecimento de mecanismos de autodisciplina por parte dos empregados. Ainda, considerando a dinamicidade do assunto no atual contexto normativo, constata-se a importância da continuidade de estudos sobre o tema, sobretudo com respaldo nas decisões judiciais a serem prolatadas sob a vigência da nova norma.

\section{REFERÊNCIAS}

AFONSO, Kleber Henrique Saconato. Teletrabalho: escravidão digital e o dano existencial por lesão ao lazer e convívio familiar. Revista de artigos do $1^{\circ}$ Simpósio sobre Constitucionalismo, Democracia e Estado de Direito, p. 716-736, jan. 2017. Disponível em: http://bit.ly/2IDJC6b. Acesso em: 23 set. 2017.

ALMEIDA, Almiro Eduardo de; SEVERO, Valdete Souto. Direito à desconexão nas relações sociais de trabalho. 2. ed. São Paulo: LTr, 2016.

ALMEIDA, Daniela Favilla Vaz de; COLNAGO, Lorena de Mello Rezende. O teletrabalho, o direito à desconexão do ambiente de trabalho e os possíveis meios de inibição da prática. Revista de Direito do Trabalho, São Paulo, v. 169, a. 42, p. 113-126, maio/jun. 2016.

BALD, Aline Graziela; TESSMANN, Cláudia. Direito à desconexão frente aos direitos e deveres do empregado no contrato de trabalho especificamente no teletrabalho. Revista Destaques Acadêmicos, Lajeado, v. 8, n. 2, p. 152-172, 2016.

BARROS, Alice Monteiro de. Curso de Direito do Trabalho. 9. ed. São Paulo: LTr, 2013. 
BETIATTO, Ricardo. Teletrabalho: a Reforma Trabalhista em contraponto com as perspectivas europeia e italiana. Revista Eletrônica do Tribunal Regional do Trabalho da $9^{a}$ Região, Curitiba, v. 7, n. 62, p. 46-56, set./out. 2017.

BRAGA, Eduardo Souza. Direito à desconexão do trabalho como instrumento de proteção da saúde do trabalhador. 2015. 163 f. Dissertação (Mestrado em Direito) - Faculdade de Ciências Humanas e Sociais, Universidade Estadual Paulista Júlio de Mesquita Filho, Franca, 2015.

BRASIL. Lei n. 13.467, de 13 de julho de 2017. Disponível em: http://bit.ly/2V9bvtz. Acesso em: 11 out. 2017.

CHRISTANDL, Gregor. La risarcibilità del danno esistenziale. Milão: Giuffrè, 2007.

DELGADO, Maurício Godinho; DELGADO, Gabriela Neves. A reforma trabalhista no Brasil: com os comentários à Lei n. 13.467/2017. São Paulo: LTr, 2017.

DUTRA, Silvia Regina Bandeira; VILLATORE, Marco Antônio César. Teletrabalho e direito à desconexão. Revista Eletrônica Tribunal Regional do Paraná, v. 3, p. 142-149, 2014. Disponível em: http://bit.ly/2Gj7Ujf. Acesso em: 7 out. 2017.

ESTRADA, Manuel Martín Pino. Teletrabalho \& Direito: o trabalho à distância e sua análise jurídica em face aos avanços tecnológicos. Curitiba: Juruá, 2014.

FINCATO, Denise Pires. Teletrabalho: uma análise juslaboral. In: STÜRMER, Gilberto (org.). Questões controvertidas de direito do trabalho e outros estudos. Porto Alegre: Livraria do Advogado, 2006. p. 45-62.

FINCATO, Denise Pires; CRACCO NETO, Heitor Barbieri. Teletrabalho: de Chappe a Nilles. Revista Justiça do Trabalho, Porto Alegre, a. 30, n. 358, p. 53-66, out. 2013.

FINCATO, Denise Pires; MARQUES, Shaiala Ribeiro de Castro Araujo. Síndrome de burnout, trabalho e tecnologia. Justiça do Trabalho, v. 33, p. 31-47, 2016.

HARFF, Rafael Neves. Direito à desconexão: estudo comparado do direito brasileiro com o direito francês. Revista Eletrônica do TRT da $4^{\text {a }}$ Região: acórdãos, sentenças, ementas, artigos e informações, Porto Alegre, a. XIII, n. 205, p. 53-74, jul. 2017.

ITÁLIA. Legge 22 maggio 2017, n. 81. Disponível em: http://bit.ly/2v6fLvo. Acesso em: 28 jun. 2018.

LEITE, Carlos Henrique Bezerra. Curso de direito do trabalho. 8. ed. São Paulo: Saraiva, 2017.

LIMA FILHO, José Sartro Fulgênico; BRASIL, Ana Larissa da Silva. Limitação da duração do trabalho na Lei 13.467/2017: repercussões no direito do teletrabalhador. Revista Juris UniToledo, Araçatuba, v. 03, n. 02, p. 154-169, abr.jun. 2018.

LUCENA, João Paulo. O teletrabalho e o controle do trabalhador à distância. Revista Eletrônica do TRT da $4^{a}$ Região: acórdãos, sentenças, ementas, artigos e informações, Porto Alegre, v. 11, n. 187, p. 50-64, dez. 2015. 
LUNARDI, Alexandre. Função social do direito ao lazer nas relações de trabalho. 2008. $190 \mathrm{f}$. Dissertação (Mestrado em Direito) - Faculdade de Direito, Centro Universitário IFEO, Osasco, 2008.

MAGALHÃES, Joalvo. 2017. Teletrabalho. In: Reforma Trabalhista 2017: o mundo do trabalho em suas mãos. Rio de Janeiro: Curso Ênfase, 2017.

MARQUES, Shaiala Ribeiro de Castro. Tecnologias e (nova) existência humana: reflexões sobre os direitos fundamentais ao lazer e ao trabalho e suas repercussões nos danos existenciais. 2017. 130 f. Dissertação (Mestrado em Direito) - Escola de Direito, Pontifícia Universidade Católica do Rio Grande do Sul, Porto Alegre, 2017.

MEDEIROS, Dárlen Prietsch. Interações entre trabalho e tecnologias: a influência da tecnologia na forma, ritmo e intensidade do trabalho. In: FINCATO, Denise Pires (org.). Novas tecnologias, processo e relações de trabalho. Porto Alegre: Sapiens, 2015. p. 491-511.

MELO, Camila Barbosa Almeida. O teletrabalho e o direito à desconexão. Revista da Esmam, São Luís, v. 10, n. 10, p. 231-249, jan./dez. 2016.

MROSS, Henry. Implantação de projeto-piloto de teletrabalho na Coordenação-Geral de Informática da Secretaria da Previdência. 2016. 74 f. Monografia (Especialização em Gestão Pública) - Escola Nacional de Administração Pública, Brasília, 2016.

NASCIMENTO, Amauri Mascaro; NASCIMENTO, Sônia Mascaro. Curso de direito do trabalho: história e teoria geral do direito do trabalho relações individuais e coletivas do trabalho. 29. ed. São Paulo: Saraiva, 2014.

NILLES, Jack M. Fazendo do teletrabalho uma realidade: um guia para telegerentes e teletrabalhadores. São Paulo: Futura, 1997.

NUNES, Talita Camila Gonçalves. O acidente de teletrabalho e a fiscalização da tecnologia da telemática: aspectos e consequências do teleassédio moral e do teletrabalho escravo. Revista de Direito do Trabalho, São Paulo, v. 167, n. 42, p. 183-208, jan./fev. 2016.

OLIVEIRA, Christina D’Arc Damasceno. O direito à desconexão do trabalhador: repercussões no atual contexto trabalhista. Revista LTr: legislação do trabalho, São Paulo, v. 74, n. 07, p. 1.1801.188, out. 2010.

PEDREIRA, Pinho. O teletrabalho. Revista LTr, São Paulo, 64, n. 5, 2000.

RESEDÁ, Salomão. O direito à desconexão: uma realidade no teletrabalho. Revista de Direito do Trabalho: RDT, v. 33, n. 126, p. 157-175, abr./jan. 2007. Disponível em: http://bit.ly/2DeumsT. Acesso em: 29 ago. 2017.

RAVAGNANI, Christopher Abreu; RODRIGUES, Raphael Marcos Baccaro. Os impactos da novel reforma trabalhista no teletrabalho. Revista Juris UniToledo, Araçatuba, v. 03, n. 02, p. 03-23, abr./jun. 2018. 
RIBEIRO, Priscila Andreoni. Teletrabalho na sociedade da informação brasileira. Sociedade Brasileira de Teletrabalho e Teleatividades, 13 out. 2016. Disponível em: http://bit.ly/2PeHoeQ. Acesso em: 30 set. 2017.

SANTOS, Michel Carlos Rocha; MIRANDA, Michelly Cardoso. A eficácia horizontal dos direitos fundamentais: a proteção à intimidade e vida privada no teletrabalho em face de era virtual. Revista de Direito do Trabalho: RDT, v. 43, n. 175, p. 95-115, mar. 2017.

SOUTO MAIOR, Jorge Luiz. Do direito à desconexão do trabalho. Justiça do Trabalho, São Paulo, v. 20, n. 238, p. 7-23, out. 2003.

STEFANO, Fabiane; ROSSI, Lucas. Por que cada vez mais empresas adotam o home office. Revista Exame, 30 maio. 2015. Disponível em: http://bit.ly/2L0isJR. Acesso em: 7 out. 2017.

TARGINO, Maria das Graças. Novas tecnologias de comunicação: mitos, ritos ou ditos? Ciência da Informação, Brasília, v. 24, n. 2, p. 194-203, 1995.

Denise Pires Fincato Pós-Doutora em Direito do Trabalho pela Universidad Complutense de Madrid. Professorapesquisadora no PPGD PUCRS. Coordenadora do Grupo de Pesquisas Novas Tecnologias, Processo e Relações de Trabalho - NTPRT - CNPq/PUCRS. Advogada. E-mail: dpfincato1@gmail.com

Julise Carolina Lemonje Graduada em Direito pela Pontifícia Universidade Católia do Rio Grande do Sul - PUCRS. Bolsista de Iniciação Científica, vinculada ao Grupo de Pesquisas Novas Tecnologias, Processo e Relações de Trabalho - CNPq/PUCRS. Advogada. E-mail: juliselemonje@hotmail.com 